\title{
Growth Pattern of Cities in India: Application of Statistical Models
}

\author{
A. S. Kadi \\ Department of Statistics \\ Karnataka University, Dharwad \\ Karnataka, India \\ E-mail: kadi_as@hotmail.com \\ B. I. Halingali \\ College of Agriculture \\ Shimoga, India
}

\begin{abstract}
Several probabilistic and deterministic (including economic) models have been proposed to predict the growth and pattern of distribution of cities by their population size. Among them Pareto family of distributions have shown a remarkable empirical regularity and the city size distribution in many countries is well approximated by these distributions. However, these models are useful to study the distribution of larger size cities satisfying certain regularity conditions. In the Indian context Pareto distribution fits well only to the distribution of cities with a population size of million plus. No such exercise has been made for other cities populated less than a million. In the present paper, an attempt has been made to characterize cities of all sizes through appropriate models applied to predict the growth pattern of cities in Indian context.
\end{abstract}

Key Words: Census data, city size, growth pattern, Pareto, exponential models, method of estimation 


\section{Résumé}

Plusieurs modèles probabilistes et déterministes (y compris économique) ont été proposés pour prédire la croissance et le schéma de la distribution des villes par la taille de leur population. Parmi ces modèles, les distributions de Pareto ont démontré une régularité empirique remarquable, et la distribution par taille des villes de nombreux pays est bien approximée par ces distributions. Cependant, ces modèles s'avèrent utiles quand il s'agit de l'étude de la distribution des plus grandes villes qui satisfont certaines conditions de régularité. Il en est de même dans le contexte de l'Inde, où la distribution de Pareto ne fonctionne bien que pour la distribution des villes comprenant une population d'un million ou plus. Aucun exercice de ce genre n'a été entreprit pour d'autres villes avec des populations de moins d'un million. Dans cet article, nous avons tenté de caractériser des villes de toutes tailles à l'aide de l'application de modèles appropriés pour prédire le schéma de croissance des villes dans le contexte de l'Inde.

Mots clés: Données de recensements, schéma de croissance, Pareto, modèles exponentiels, méthode d'estimation

\section{Introduction}

The study of growth and distribution of cities by their size has gained an increasing importance in the characterization of urban process. Several probabilistic and deterministic (including economic) models have been proposed to study the distribution of cities by their size. Among them, Zipf law, Pareto distribution, Gibrat's law and Rank Size Rule, all belonging to a single family, have shown a remarkable empirical regularity. In many countries, the city size distribution is well approximated by these laws of distributions. However, the empirical evidences show that the applications of these models are restricted to study the distribution of cities with population size more than a million, satisfying certain regularity conditions. No effort has been made to study the cities with population less than a million.

CSP 2010, 37.1-2: $125-150$ 
In the Indian context, it has been shown that Pareto distribution fits well only to the distribution of cities with population size of million plus, because they have reached the highest level of urban population with constant growth rate, and their growth is more influenced by economic development. This state is called "state of urban maturity" (Rosen and Resnick 1980; Kadi and Megeri 2009). This distribution fails to fit other cities in India that have population strength of less than a million, because they have not yet reached the highest level of urban population and their growth rates are influenced by natural increase of population rather than inmigration and economic development (Megeri 2002).

In this paper we attempt to characterize Indian cities by their size and formulate appropriate mathematical models based on their trend of growth over time. First we present concepts and definitions used in this paper. Next, we give an overview of the growth and distribution of urban population in India, followed by a brief review of the literature on city growth models. Finally, we specify and apply various growth models to cities of different size based on Indian census data and discuss our findings.

\section{Concepts and Definitions}

It is important to explain the concepts used in this paper. It is also important to understand the relevant terms used by the Census of India 2001 (Registrar General and Census Commissioner India 2001). The relevant concepts and definitions are given below:

\section{Rural-Urban Areas}

Population data are classified separately for rural and urban areas. The unit of classification is 'town' for urban areas and 'village' for rural areas. In the Census of India 2001, the definition of urban area is as follows:

a) All places with a municipality, corporation, cantonment board or notified town area committee, etc., (Called Statutory Towns).

b) A place which satisfies the following three criteria simultaneously (Called Census Towns):

i) a minimum population of 5,000

ii) at least 75 per cent of male working population engaged in non-agricultural pursuits; and 
iii) a density of population of at least 400 persons per sq. $\mathrm{km}$ (1,000 per sq. mile).

For identification of places, which would qualify to be classified as 'urban', all villages, which, as per the 1991 census had a population of 4,000 and above, a population density of 400 persons per sq. $\mathrm{km}$. and having at least 75 per cent of male working population engaged in non-agricultural activity, were considered. To work out the proportion of male working population referred to above against b) (ii), the data relating to workers were taken into account.

Apart from these, the outgrowths (OGs) of cities and towns have also been treated as urban under 'Urban Agglomerations': examples of out-growths are railway colonies, university campuses, port areas, military camps, etc., that may have come up near a statutory town or city but within the revenue limits of a village or villages contiguous to town or city. Each such individual area by itself may not satisfy the demographic criteria laid down at (b) above to qualify it to be treated as an independent urban unit, but may deserve to be included with the towns as a continuous urban spread. Thus, the town level data, wherever presented, includes the data for outgrowths separately of such towns and also of town plus outgrowth (s) population.

\section{Classification of Cities}

Similar to 1991 Indian Census and in 2001 Censuses also the urban units have been classified into the following six categories based on the size of the towns.

Towns with population of 100,000 and above are called Cities, and towns with a population size one million and above are called Primate Cities. In the Indian context, the census data on number of cities and growth pattern classified into six categories are based on their size. The growth and pattern of distribution of cities differ with categories. Hence this leads to formulate different models to describe their growth pattern and their prediction. Before taking up this problem of formulation of models for analysis, we shall consider a brief account of growth in a number of cities and their size in India from 1901 to 2001.

\section{Growth and Distribution of Cities}

Before 1950, that is, before the Independence of India, the size and the growth rate of the urban population and the transfer of individuals from rural to urban areas were very slow (Mohan 1985; Moonis Raza et al. 1981). Table 1 gives the number of towns in each census during 1901-2001. The table shows an

CSP 2010, 37.1-2: 125-150 
Predicting the Growth Pattern of Cities in India: Application of Statistical Models

increasing trend in the number of towns and total urban population living in these towns from 1921 to 2001 . We find fluctations in the number of towns from 1961 onwards. This is because of the declassification of some towns and the addition of some other (Bose 1978; Megeri 2002). From Table 1, we find that, in spite of discontinuity in the growth of total population at some points during 1901-2001, the size of the urban population increased continuously from 25.85 millions to 285.35 millions.

\section{Size Classification of Cities}

\begin{tabular}{cc}
\hline Size Class & Population \\
\hline & \\
I & $\mathbf{1 0 0 , 0 0 0}$ and above \\
II & $\mathbf{5 0 , 0 0 0}-\mathbf{9 9 , 9 9 9}$ \\
III & $\mathbf{2 0 , 0 0 0}-\mathbf{4 9 , 9 9 9}$ \\
IV & $\mathbf{1 0 , 0 0 0}-\mathbf{1 9 , 9 9 9}$ \\
V & $\mathbf{5 , 0 0 0}-\mathbf{9 , 9 9 9}$ \\
VI & Less than $\mathbf{5 , 0 0 0}$ \\
\hline
\end{tabular}

In Indian Census, the urban units have been classified into six categoriesClass-I to Class-VI based on the size of the towns (For details of classification and their demerits see Source of Table 2 and Nanda 1991). In 1901, about 1917 cities/towns accommodated all urban dwellers and then in 2001, the number of cities increased to 5151. In 1901, out of 1917 different city size classes, about 1701 belonged to the city size of Class IV, V and VI, which contained 90 percent of the total urban population. During the last 50 years, about 1000 cities were added at the rate of 20 cities per annum to the number of 1901, and not much variation was found in the percentage share of urban population of each city size category. Until 1951, small towns of category IV, V and VI were found to be large in number. In 1951, the number of cities of these categories altogether was found to be 2499; out of total 3060 cities of all categories, residence facility is given to 18 million urban populations, covering only 29 percent of total urban population. Most of these towns cater such service as materials for their daily need, schooling, health, market for their products, etc., to the surrounding villages. It is surprising to note that the trend of increase in the number of cities and size of population growth of Class-I, Class-II and Class-III cities since 1901 till recent census, was not affected. 
Table 1

Urbanization Trends in India by Census Year: 1901 - 2001

\begin{tabular}{ccccc}
\hline Census Year & $\begin{array}{c}\text { Number of } \\
\text { Towns/UA's }\end{array}$ & $\begin{array}{c}\text { Total } \\
\text { Population }\end{array}$ & $\begin{array}{c}\text { Urban } \\
\text { Population }\end{array}$ & $\begin{array}{c}\text { Percent } \\
\text { Urban }\end{array}$ \\
\hline $\mathbf{1 9 0 1}$ & 1827 & $238,396,327$ & $25,851,873$ & 10.84 \\
$\mathbf{1 9 1 1}$ & 1815 & $252,093,390$ & $25,941,633$ & 10.29 \\
$\mathbf{1 9 2 1}$ & 1949 & $251,321,213$ & $28,086,167$ & 11.18 \\
$\mathbf{1 9 3 1}$ & 2072 & $278,977,238$ & $33,455,989$ & 11.99 \\
$\mathbf{1 9 4 1}$ & 2250 & $318,660,580$ & $44,153,297$ & 13.86 \\
$\mathbf{1 9 5 1}$ & 2843 & $361,088,090$ & $62,443,709$ & 17.29 \\
$\mathbf{1 9 6 1}$ & 2365 & $439,234,771$ & $78,936,603$ & 17.97 \\
$\mathbf{1 9 7 1}$ & 2590 & $548,159,652$ & $109,113,977$ & 19.91 \\
$\mathbf{1 9 8 1}$ & 3378 & $683,329,097$ & $159,462,547$ & 23.34 \\
$\mathbf{1 9 9 1}$ & 3768 & $844,324,222$ & $217,177,625$ & 25.72 \\
$\mathbf{2 0 0 1}$ & 5161 & $1,027,015,247$ & $285,354,954$ & 27.78 \\
& & & & \\
\hline
\end{tabular}

Source: Provisional population totals: Rural-Urban Distribution, Census of India, 1901-2001, New Delhi.

The number of cities of smaller size IV, V and VI Classes and their percentage share of urban population have shown a steady decline as a result of promotion of these cities to the higher categories, while cities in other size classes have shown a greater tendency of increase in their number as well as in their population size and percentage share of urban population (See Tables 2 and $3)$. For instance, the number of cities and towns of Class-VI size category increased from 503 to 629 during 1901 and 1951, while during 1951 and 2001, the number decreased to 227. More or less, a similar trend was noticed with respect to towns of Class-V size. On the other hand, the number of Class-I cities have shown a steady and slow increase in their number from 25 with 1.33 percentage share of urban population to 49 in number with 2.02 percent urban population between 1901 and 1941. By 2001, their number had increased to 423, accounting for 138.8 million urban populations, which formed 62 percent of the urban population. Similar pattern has been observed with Class II, III and IV cities/towns (See Table 2 and Table 3) 


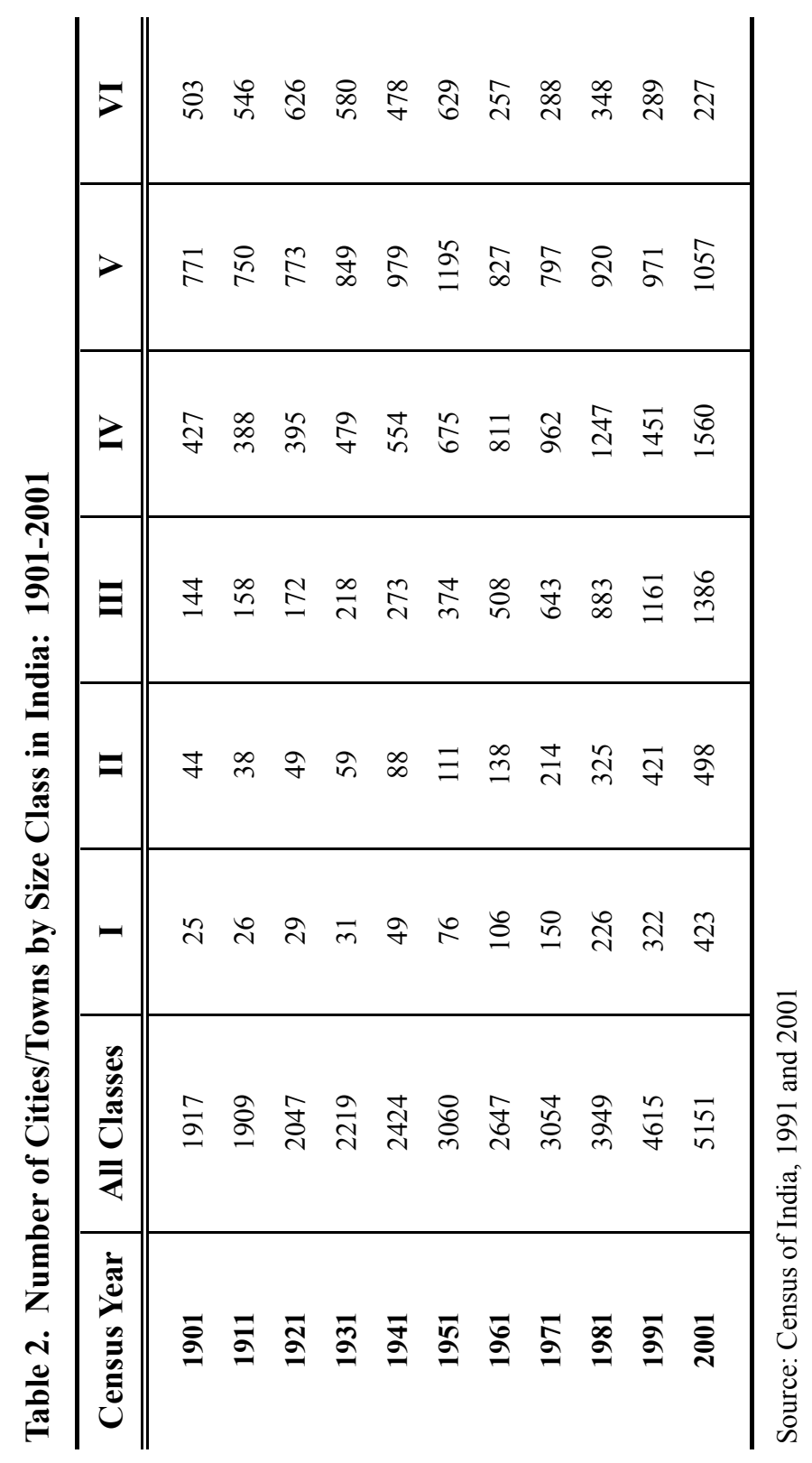




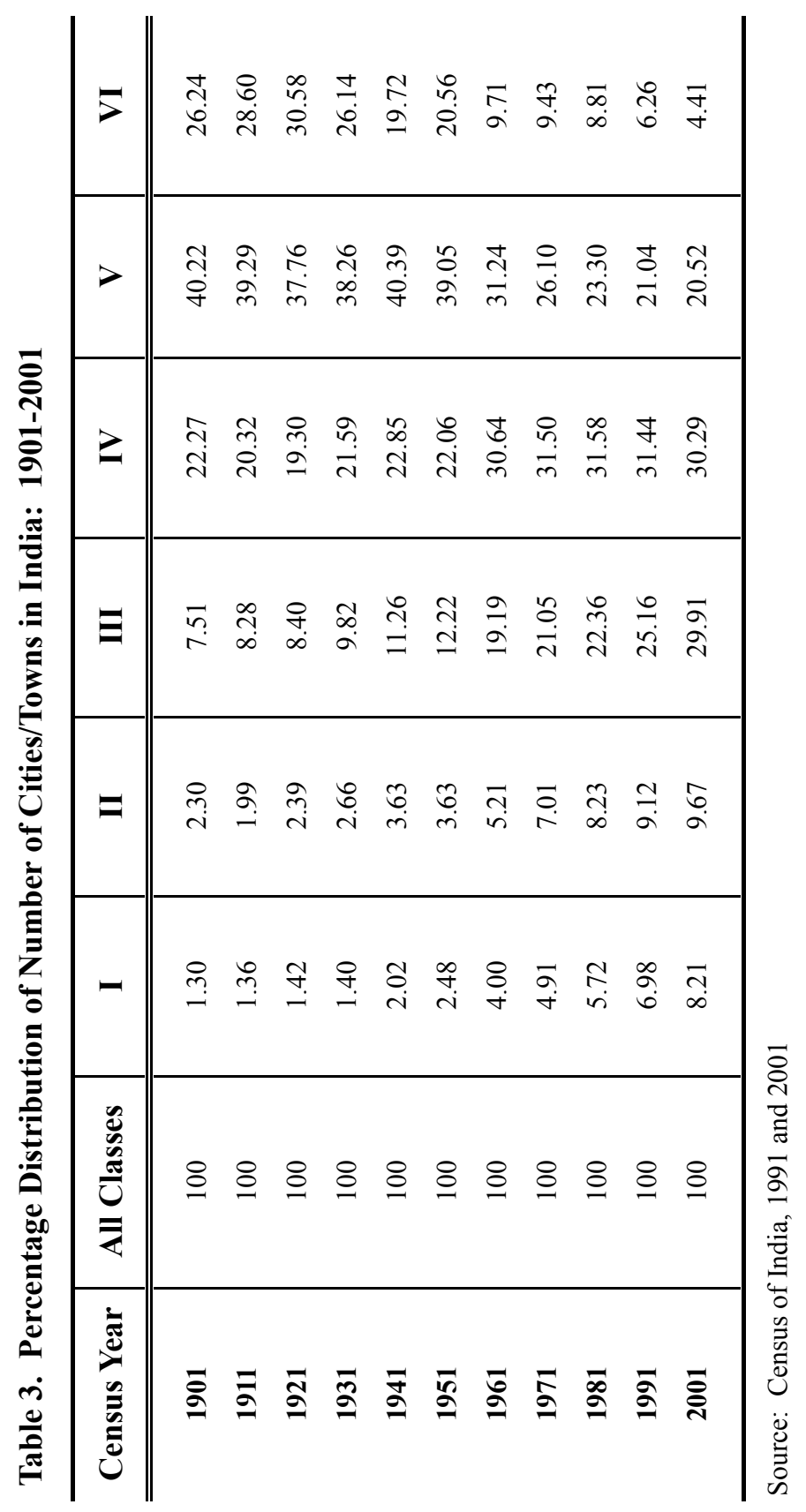


Predicting the Growth Pattern of Cities in India: Application of Statistical Models

In India, the process of urbanization has been completely governed by Class-I cities. This clearly indicates the spatial direction of developmental process that is taking place over the decades. Class-I cities alone account for 57 (See Table 4) percent of the total urban population in 1991. Thus, class-I cities are growing at the cost of other size classes, and their growth is much faster than other cities and towns in the country. Most of the development that has taken place in India is almost strengthening the urban economy, and is concentrated largely in cities of larger size, specifically in Metropolitan cities with a population size of more than a million. In 1901, there was only one such city, namely, Calcutta and in 1911 one more city Mumbai (Its earlier name was Bombay) had been added. Till 1941 only these two were the cities of this category. In 1981, their number increased to 12, and by 1991 the number of such cities increased to 23, accounting for one thirds of the country's urban population, and 8.33 percent of total National population. The exponential growth rates of these cities for four successive decades are given in Table 2.

During 1901-2001, irrespective of the state of the country, cities under Categories- I to IV have shown consistent increase in their number, whereas in the other last two categories, cities in category- $\mathrm{V}$ have increased in number after greater set back during the period 1941-51, owing to displacement of population from Pakistan at the time of independence and reorganization of state boundaries, and application of rural-urban concept during 1951 census and subsequent modifications in the definitions have affected the number of cities, specifically in Category-V and VI, as a result of which there was a break in their trend. But cities of Category-I, II and III have shown slow but steady increase in their number during the period from 1901 to 1941 , and in the later period, a large number of such cities have come up as a result of upward transition of cities from lower category to upper categories.

Figure 1 clearly shows that after 1941 cities of other categories, except class-I, have shown continuous decline in their growth. Hence after independence, the process of urbanization has been completely governed by class-I cities. Class-I cities alone account for 62 percent of the total urban population in 2001. Thus, Class-I cities are growing at the cost of other size classes, and their growth is much faster than that of other cities and towns in the country.

Another important major change is the gradual shift in the number of cities from lower size categories to cities of categories of larger size. More cities of size Class-IV, Class-V and Class-VI have been transferred to the next higher size categories. Some cities have jumped more than two size classes due to rapid growth of their population. This phenomenon was also true in cities of other size categories (See Tables 2 and 3). During 1901-1941, more than 82 percent of urban population was concentrated in cities of class-III and below category, whereas in the later period the momentum of concentration increased towards Class-I, Class-II and Class-III cities. These cities of higher order have increased

CSP 2010, 37.1-2: $125-150$ 


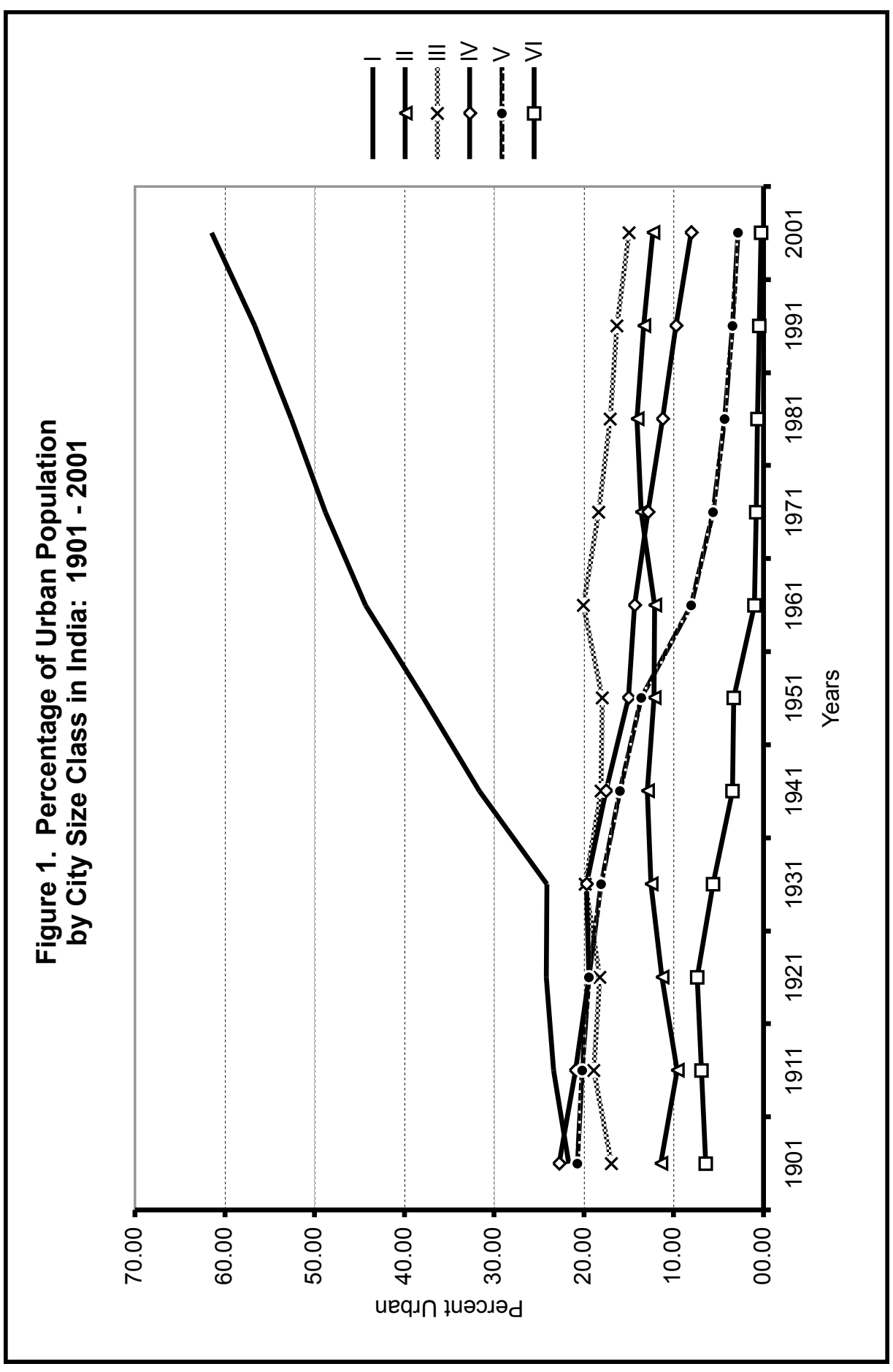

CSP 2010, 37.1-2: 125-150 
Predicting the Growth Pattern of Cities in India: Application of Statistical Models

in number at the cost of cities of lower category, and cities of smaller size, specifically Class-VI cities, have consistently declined in number (See Table 4).

However, the pattern of increase in the number of class-I cities and their population increases over a decade at a greater speed, while the percentage of urban population in cities of other categories shows moderate increase during the period from 1901 to 1941 , and during the later period, cities of other categories have shown, more or less, a similar pattern of decline in the percentage of urban population. Again, among these, cities of Class-VI size have shown greater fall in their number and percentage of urban population after 1941, which may be due to greater number of transition or out migration to cities of other categories. To describe this differential pattern in the increase or decrease in the size or number of cities in different categories, different models are needed.

\section{City Growth Models}

Considerable literature has been accumulated to generalize the growth of cities, but so far no success has been made to predict the city growth process (Gibrat 1931; Zipf 1949; Champernowne 1953; Simon 1955; Rosen and Resnick 1980; Henderson 1982; Mills and Becher 1986; Gabaix 1999). Gibrat Law (1931) is the earliest literature which states that, for a fixed number of cities, over a period of time, their size grow stochastically with common mean and variance, the growth rate equal to mean city size growth rate of cities of different sizes.

Zipf model (1949) for cities is described as the probability that the size-S of a city, greater than some fixed size of population of a city $\mathrm{x}$ is proportional to $1 / \mathrm{x}$,

$$
\mathrm{P}(\mathrm{S}>\mathrm{x})=\mathrm{A} / \mathrm{x}^{\alpha} \text { with } \mathrm{A} \text { as constant. }
$$

In empirical studies, Zipf found $\alpha=1$ as a bound for the distribution, and this leads to the rank size distribution (See Lange, 1962). A remarkable empirical regularity is that the rank size distribution is well approximated by the Pareto Distribution (1897), and is given by the distribution function:

$$
\mathrm{F}(\mathrm{x})=1-(\mathrm{s} / \mathrm{x})^{\mathrm{a}}, \mathrm{s}>0, \mathrm{a}>0 \text { and } \mathrm{x}>0
$$

$$
\text { where } F(x)=P(X \leq x)=P(\text { rank of a city } \leq x)
$$




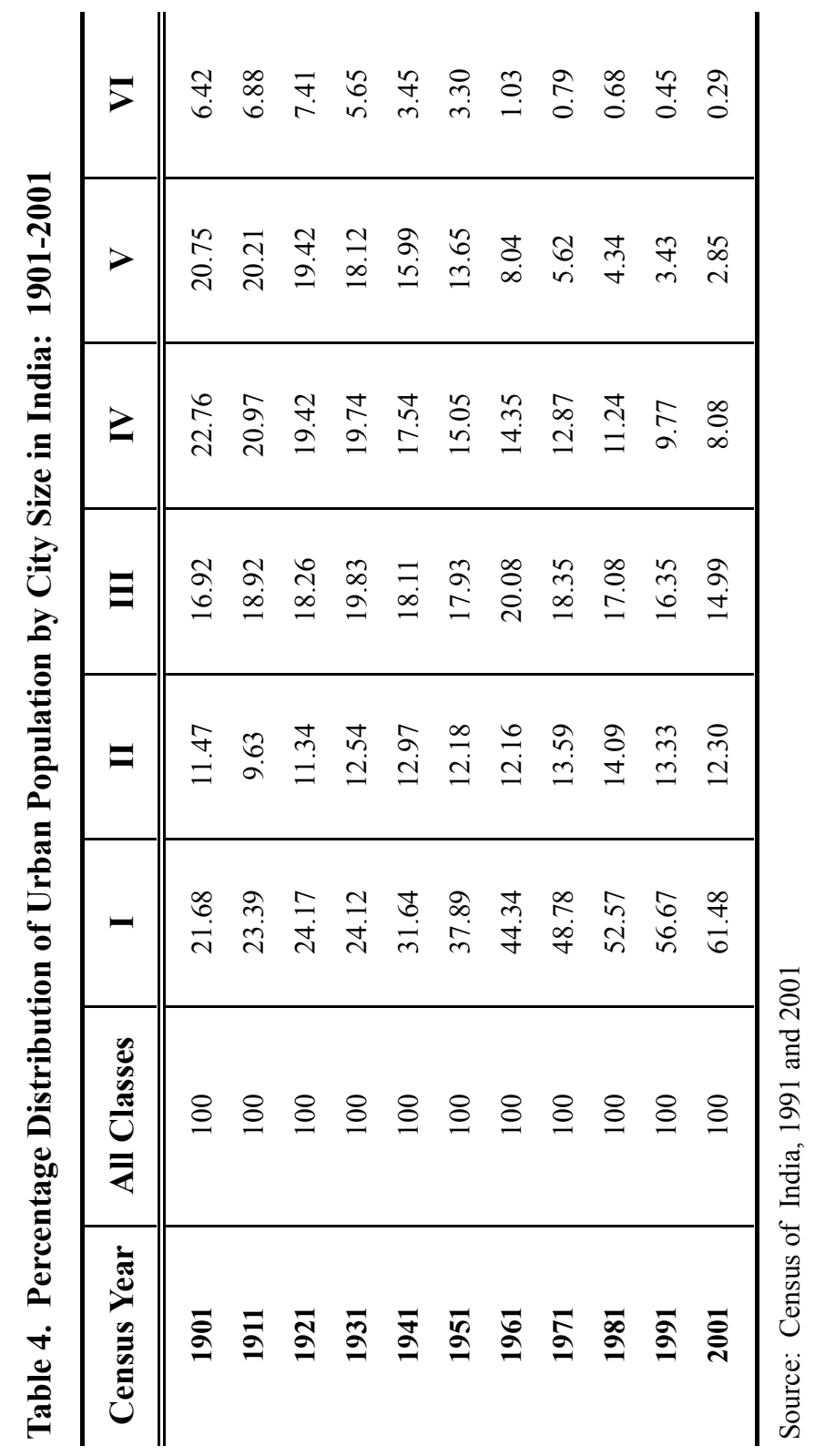


On the log scale cumulated Pareto probabilities (proportions) show a linear model implying increases in the $\mathrm{x}$ values will show further reduction in $\log (\mathrm{s}(\mathrm{x}))$ (See Lange 1962). Therefore, when the rank size distribution is applied to cities, it fits only the cities of large population size having urban maturity, and is not applicable to cities with small size of population. Thus many of the leading researchers (Champernowne 1953; Rosen and Resnick 1980; Henderson 1982) on the topic have concluded that this model is not successful in providing satisfactory explanation for the regularity. Cordoba (2003), in his theoretical work on the distribution of city size, suggested that only a specific Markov Process can generate Pareto distribution for city size, and gives an economic explanation for the regularity.

In theoretical investigations Champernowne (1953), Simon (1955) and Gabaix (1999) have shown, by using central limit theorem, that Gibrat Law, or proportional growth, Zipf law and rank size rule, all can lead to Pareto distribution under certain conditions. More precisely, if a stochastic variable follows a growth process that is independent of the position of the variable, then its limiting distribution follows Pareto distribution.

Based on the empirical evidence, David Cuberes (2004) has questioned the suitability of Gibrat's Law to city size distribution. The method used to fit the distribution can also be problemmatic. Alperovich $(1988,1993)$ applied rank size rule and estimated the coefficients by using Ordinary Least Square (OLS) method, and examined the coefficients by using t-test. He found that the distribution pattern of most of the countries did not support the rank size rule. Dobkins and Ioammides (2000) recommended using maximum likelihood estimator proposed by Hill (1975), but Soo's (2005) results did not support this alternative.

Rosen and Resnick (1980) applied this model on 50 largest administrative urban areas in 44 countries, and Soo (2005) made an international comparison by using updated data of 73 countries, but the estimate of $\alpha$ exceeded unity. This questions the validity of rank size rule as well as the family of Zipf's model (Nishiyama and Osada 2004).

Krugman (1996) and Fujita et al. (1999) have concluded that most of the city growth models are deterministic and cannot adequately account for observed change in the population size of a city. These models usually predict the equilibrium size of cities as a result of the interplay between positive and negative externalities. The models also predict that urban growth mainly occurs through increase in the number of cities. This prediction conflicts both with the idea of proportional growth and stabilization of urban system as the number of cities levels off. 


\section{Application of Models}

It is clear that most of the existing models are related to Pareto Distribution, and fit only the cities of larger size, satisfying certain regularity conditions. Formulation of generalized model to fit cities of any population size seems to be a rather complex exercise when cites are governed by different regularities. The growth of some cities may be governed by their growth in economy, that of some is governed simply by their service to the surrounding villages and other may be due to historical reasons. Thus, the study of city growth models remains incomplete until we develop appropriate model(s) to account for differential growth pattern, prediction of future size and city size transition over a period of time.

As noted, in the Indian context, cities have been classified into six categories based on their population size. After independence (in 1947), concentration of urban population in Class-I cities is increasing consistently, and are growing at the cost of other size cities. As a result, the growth of other cities has declined. Some of the cities (Class I to Class V) have similar pattern of growth, although they differ in their growth rate, while very small population size cities - Class VI have experienced severe set back in terms of their number and growth rate. Thus, we endeavour to formulate suitable models to explain and predict present and future growth trends of cities in each of the classes.

\section{Model for Class-I Cities}

As discussed, Pareto distribution fits well to a particular class of cities, namely, those cities tending to attain urban maturity. In Indian context, Class-I cities are of this nature. They have attained urban maturity, and are about to reach equilibrium conditions as their growth in population size is more or less governed by economic development (Megeri, 2002). Zipf Model (1949), which belongs to Pareto family, based on rank size rule, well approximated by Pareto distribution (Rosen and Resnick 1980), has been chosen to fit the city size distribution of class-I cities. Zipf model is defined as:

$$
\mathrm{C}_{\mathrm{k}}=\mathrm{C}_{1} \mathrm{k}^{-\mathrm{z}}
$$

Given that $\mathrm{P}(\mathrm{S}>\mathrm{k})=\mathrm{C}_{1} \mathrm{k}^{-\mathrm{z}}$ is the proportion of cities with size greater than $\mathrm{k}$ and relative rank is $\mathrm{C}_{\mathrm{k}} / \mathrm{r}$. Where $\mathrm{C}_{\mathrm{k}}$ is the population of city of rank $\mathrm{k}, \mathrm{C}_{1}$ is the population of the largest city and $\mathrm{z}$ is a constant to be determined.

In most of the studies, the parameter $\mathrm{z}$ is estimated by ordinary least squares, but here the non-linear regression method is used (Draper and Smith 1998). This method allows us to specify a starting value for the parameter, preferably as close as possible to the expected final solution. By applying the

CSP 2010, 37.1-2: $125-150$ 
Predicting the Growth Pattern of Cities in India: Application of Statistical Models

above procedure, we have fitted the city size distribution for Class-I cities for the decennial Indian census data 1991 and 2001 (See Table 5 and Figure 2).

\section{Model Specification for Class-II to Class-V Cities}

It is found that the city size distribution for these categories does not follow Pareto (or Zipf) model, because the size of the city population decreases over time. These cities are deviating from equilibrium conditions and also urban maturity. Based on the empirical figures given in Tables 2 and 3 and from Figure 1, it has been observed that the cities of class-II to V have some common pattern in their trends over time, with little variation in the growth rates. We propose exponential models as they allow differential growth pattern to fit these cities separately for each group. The proposed exponential growth model is given by:

$$
\mathrm{C}_{\mathrm{k}}=\mathrm{C}_{1} \mathrm{e}^{-\mathrm{kz}}
$$

Where $C_{k}$ is the population of city of rank $k, C_{1}$ is the population of the largest city and $\mathrm{z}$ is a constant to be determined. Here again we prefer the iterative nonlinear regression method proposed by Levenberg-Marquardt for estimating the parameters. This model fits well the city size distributions of class-II to class-V cities for 1991 and 2001. The parameters are estimated separately for each class of cities. The fitted graphs are presented in Figures 3 to 6 respectively for cities of Class-II to Class-V.

\section{Model Specification for Class-VI Cities}

For cities of size Class-VI, none of the above models fits well since the pattern of growth rate of these cities differs from that of the cities of other classes. From Table 2 we may observe that, during the period from 1921 to 2001, the growth rate and also the numbers of such cities (See Table 3) are declining consistently, and the data clearly shows that the cities of other categories are growing at the cost of these cities. Moreover, they exhibit a declining trend and exemplify a linear form. Therefore, we prefer the fourth degree polynomial model, which is specified as:

$$
\mathrm{Y}_{\mathrm{k}}=\mathrm{a}_{0}+\mathrm{a}_{1} * \mathrm{k}+\mathrm{a}_{2} \mathrm{k}^{2}+\mathrm{a}_{3} * \mathrm{k}^{3}+\mathrm{a}_{4} * \mathrm{k}^{4}
$$

Where, $\mathrm{Y}_{\mathrm{k}}$ is the population size of a city with rank $\mathrm{k}$, and $\mathrm{a}_{\mathrm{i}}, \mathrm{i}=0,1,2,3,4$ are coefficients to be determined. The model fits well to the observed distribution of city sizes. The fitted graphs are given in Figure 7 for 1991 and 2001.

CSP 2010, 37.1-2: $125-150$ 


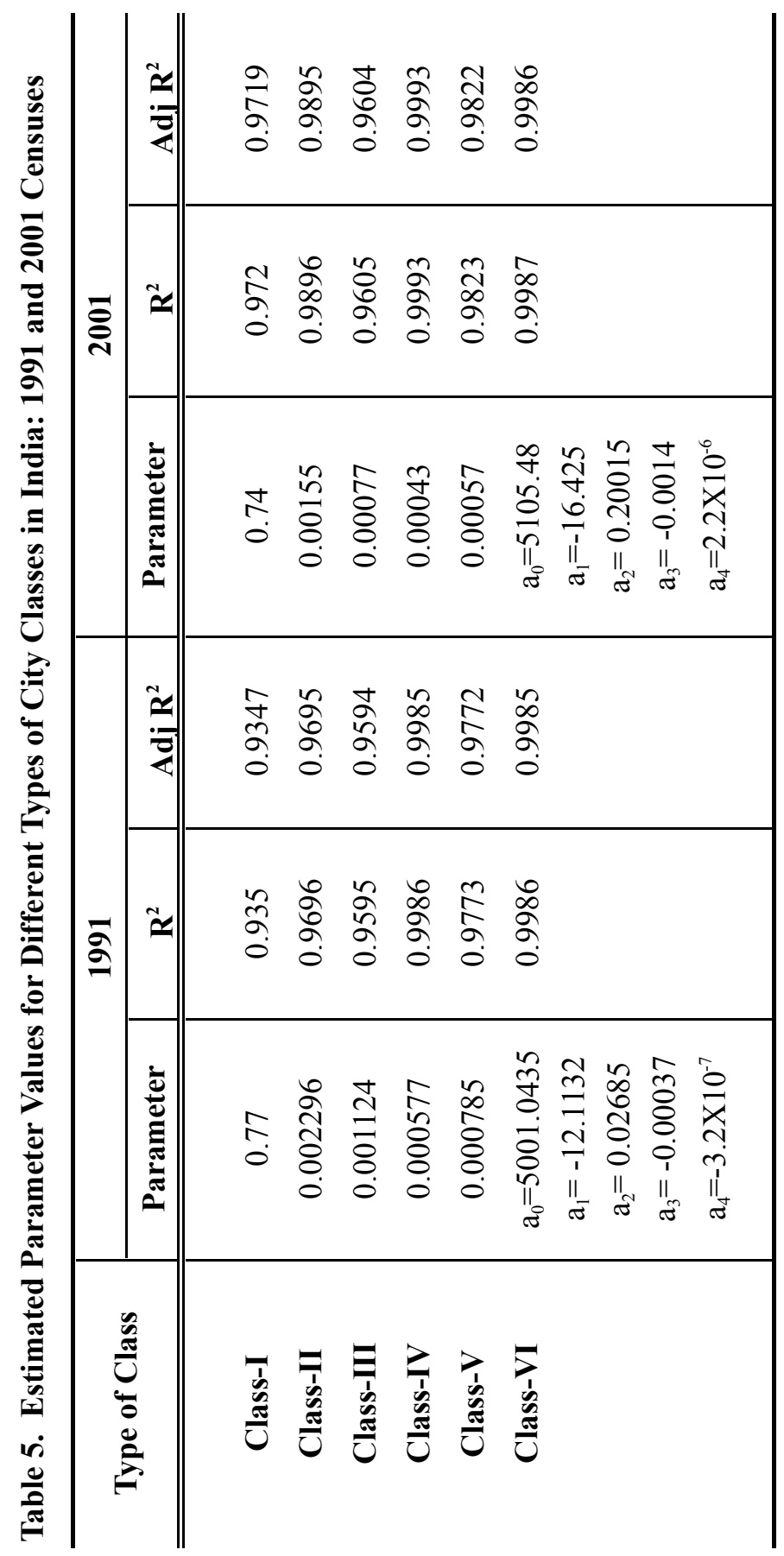


Predicting the Growth Pattern of Cities in India: Application of Statistical Models

Figure 2. Fitting of Class I Cities in India: 1991 and 2001
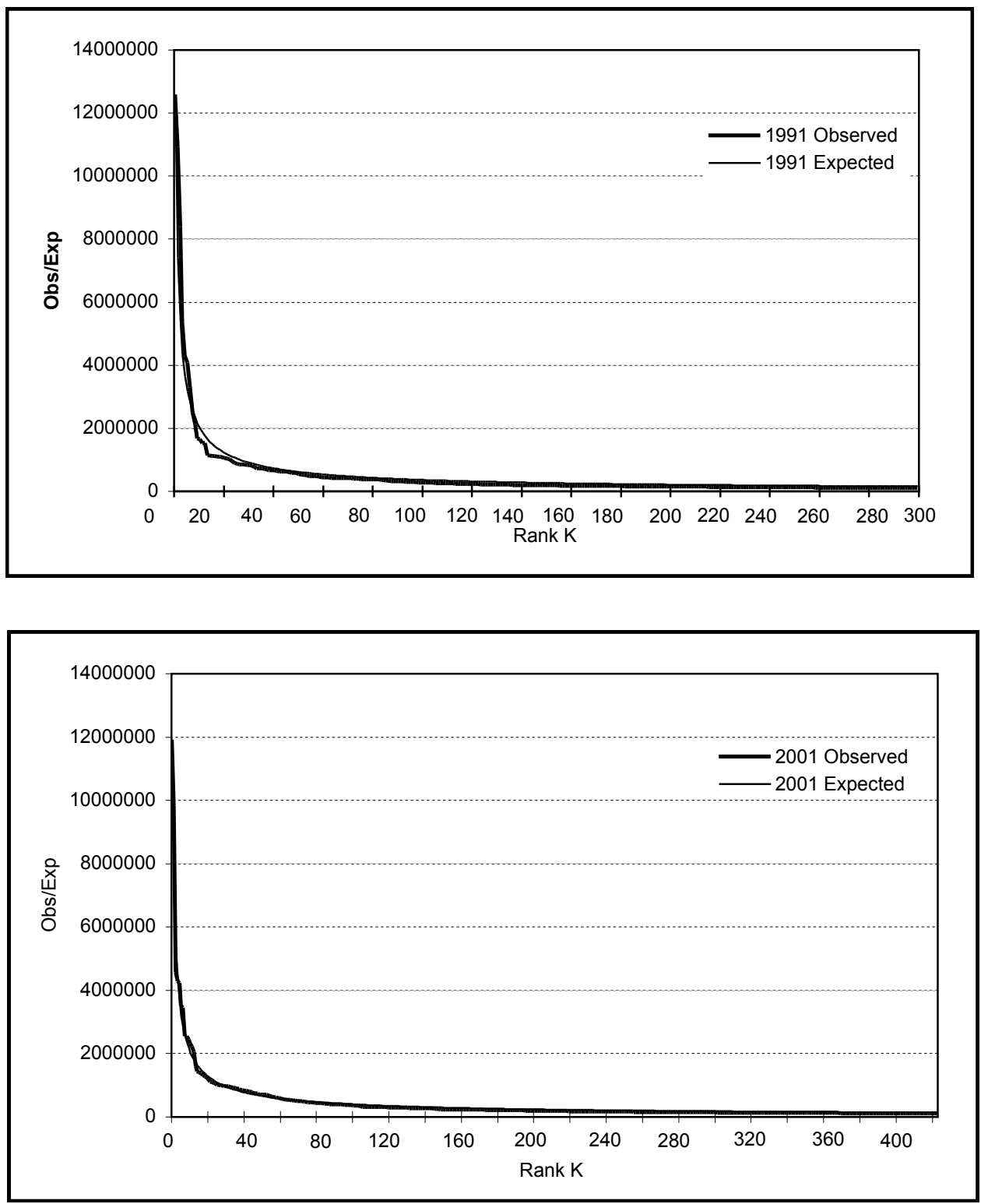

CSP 2010, 37.1-2: 125-150 
Figure 3. Fitting of Class-II Cities in India: 1991 and 2001
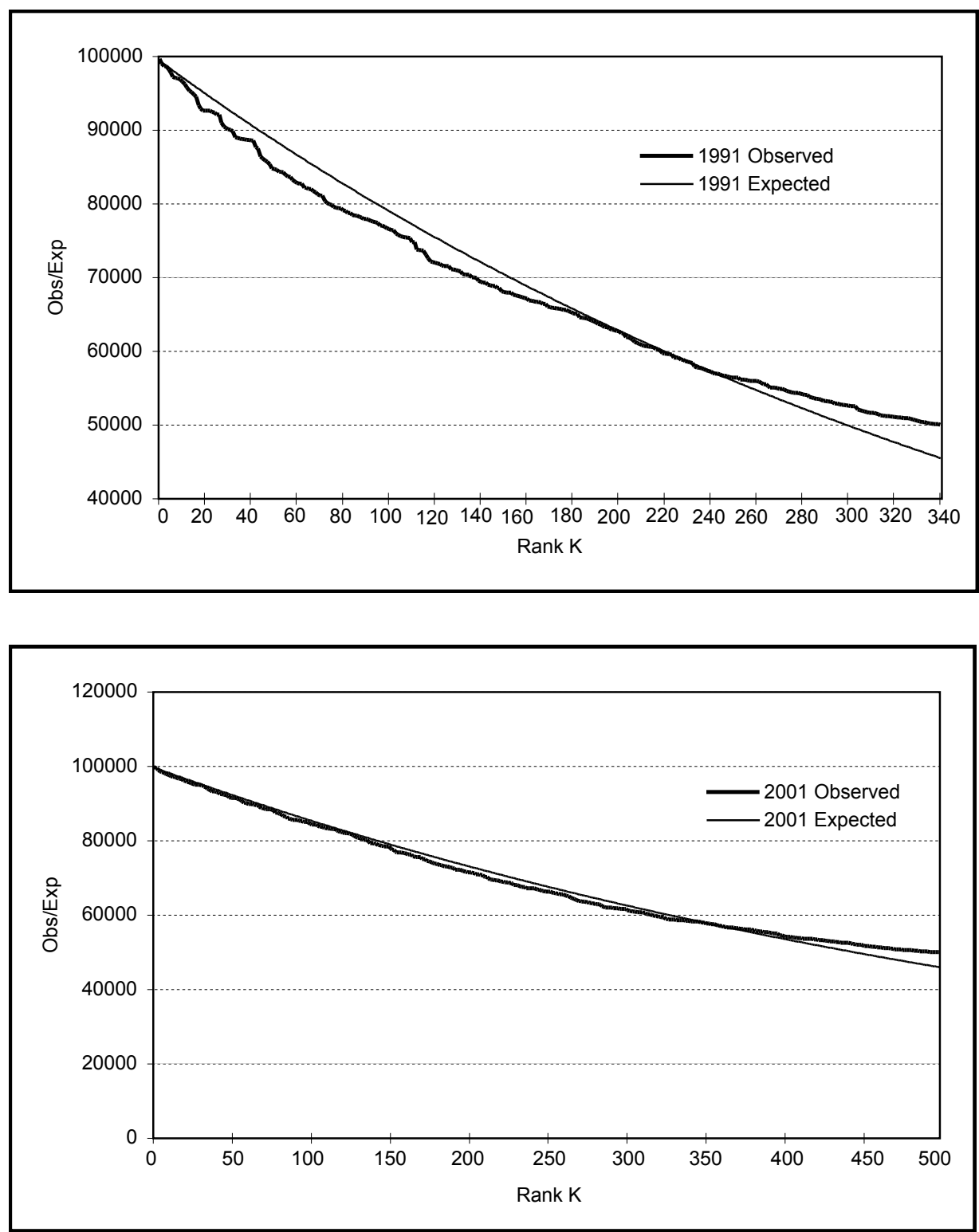

CSP 2010, 37.1-2: 125-150 
Predicting the Growth Pattern of Cities in India: Application of Statistical Models

Figure 4. Fitting of Class-III Cities in India: 1991 and 2001
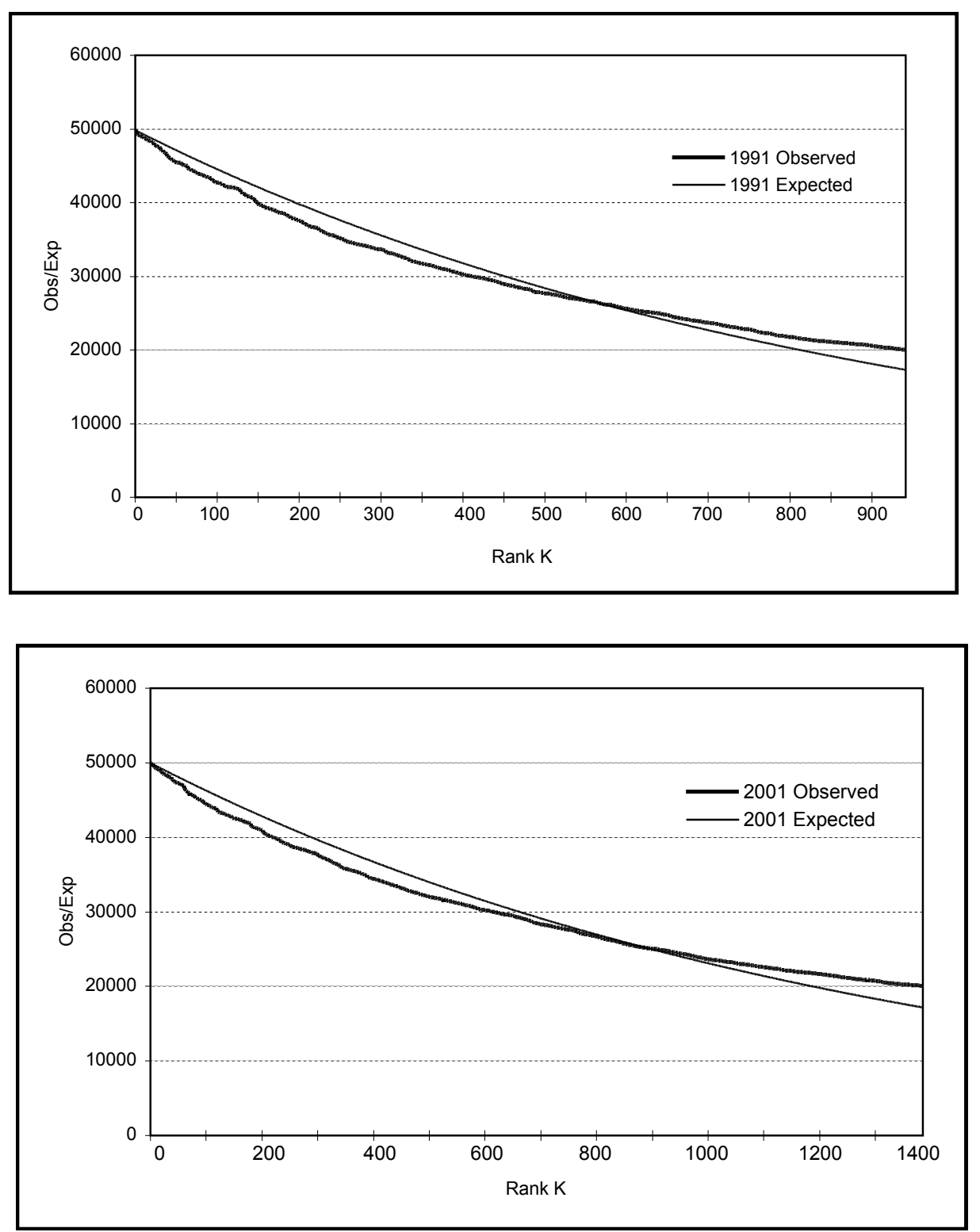
Figure 5. Fitting of Class-IV Cities in India: 1991 and 2001
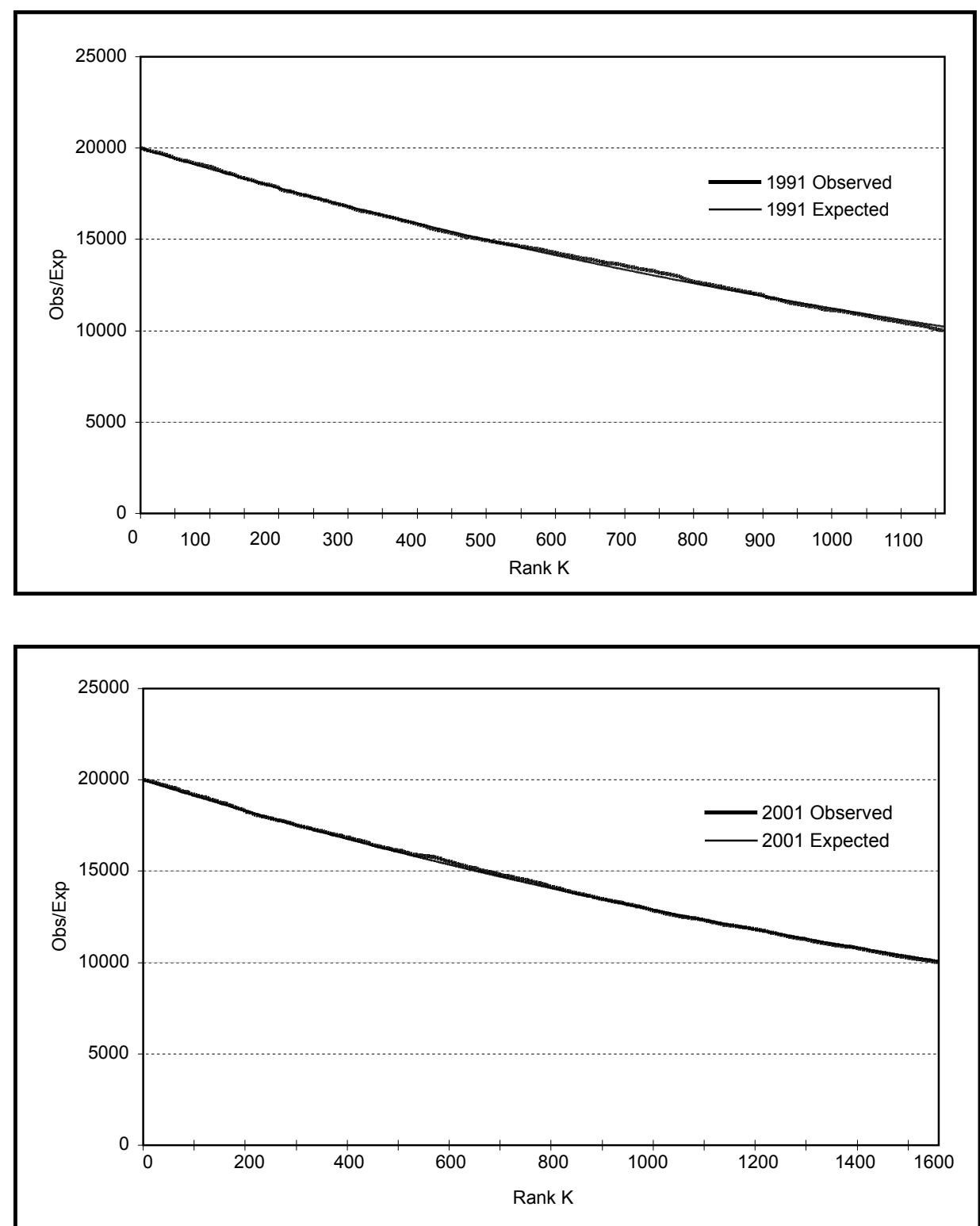
Predicting the Growth Pattern of Cities in India: Application of Statistical Models

Figure 6. Fitting of Class-V Cities in India: 1991 and 2001
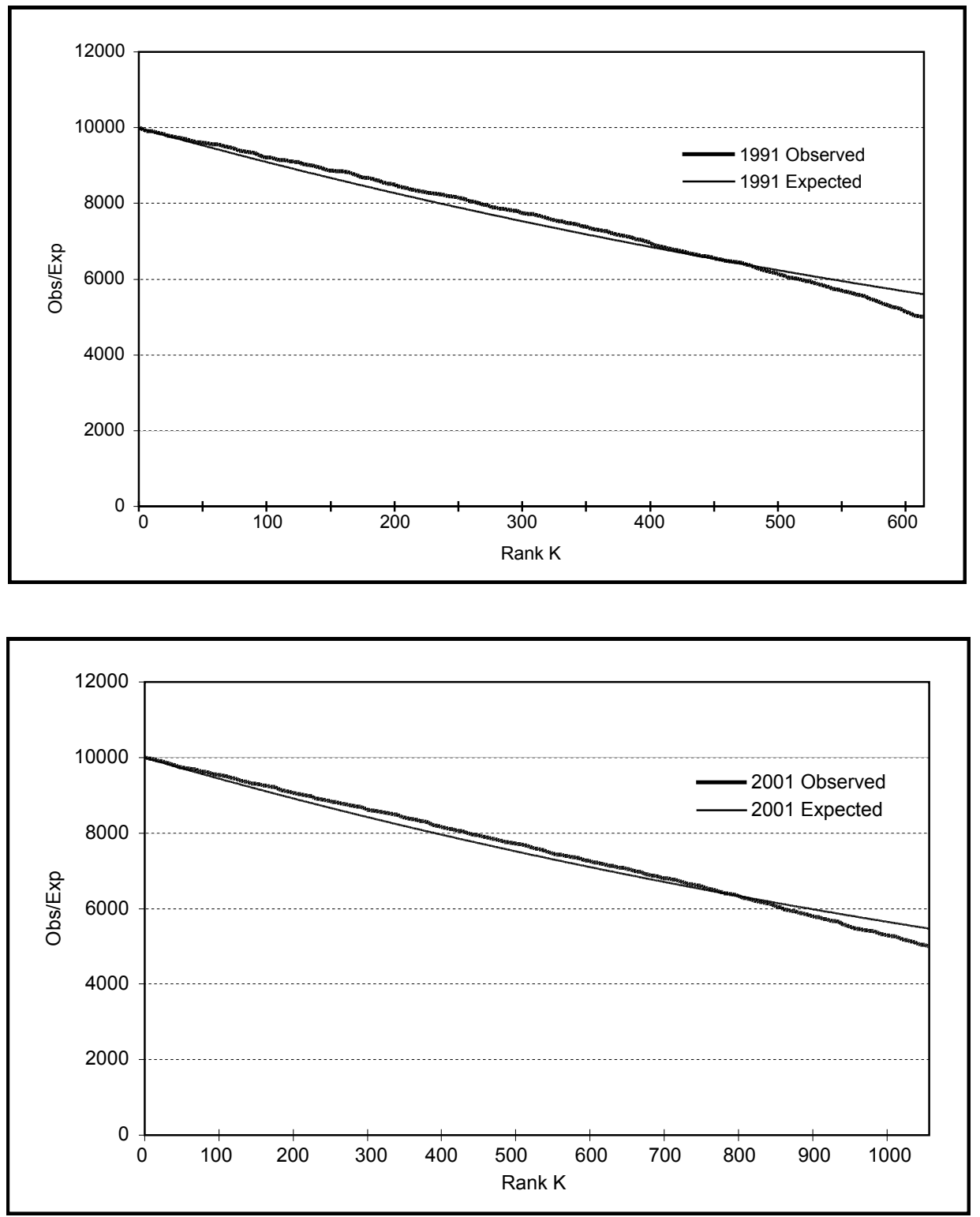
Figure 7. Fitting of Class-VI Cities in India: 1991 and 2001
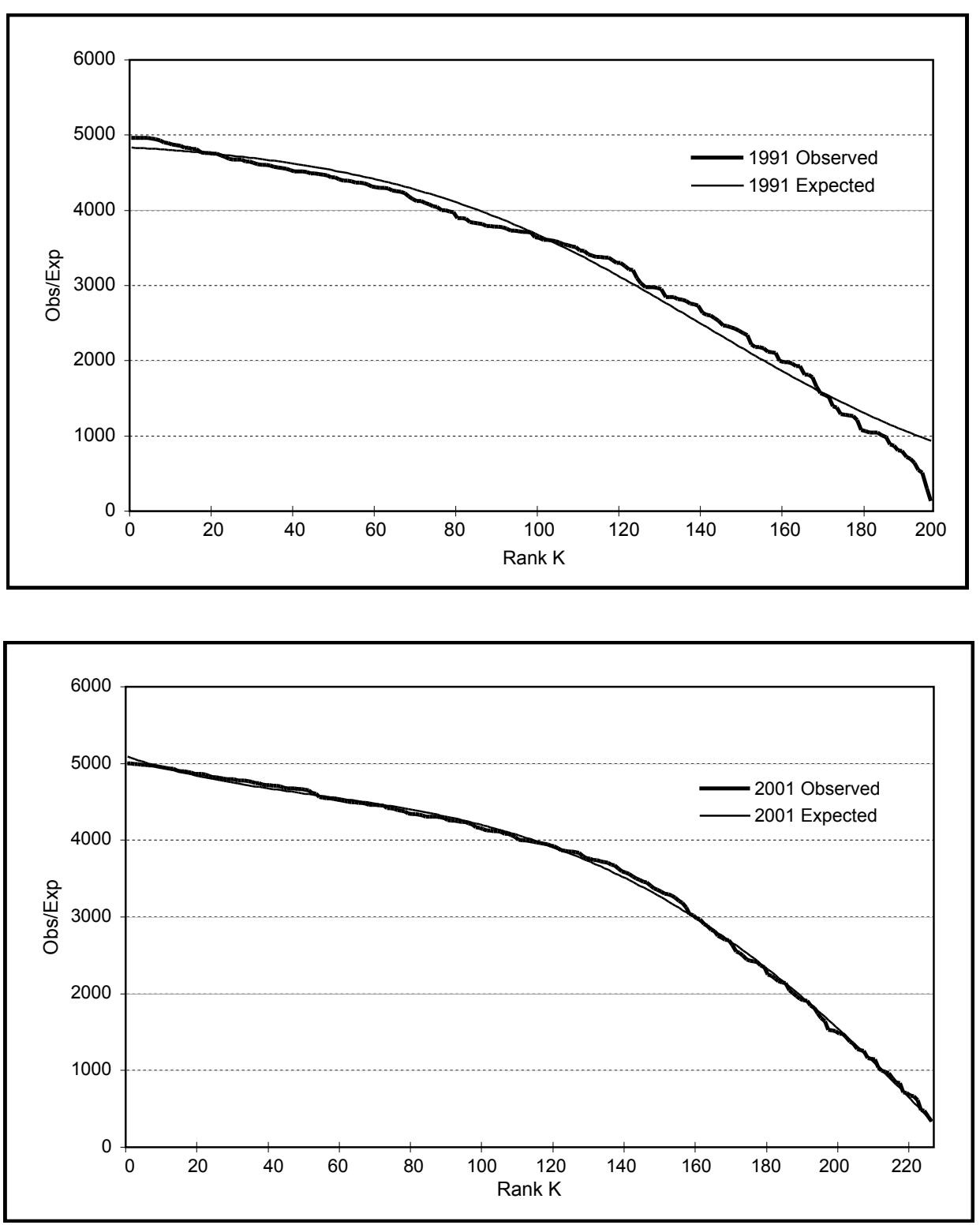


\section{Results and Discussion}

We studied the concentration of urban population in Class-I cities in India by using Pareto distribution. The estimated 1991 and 2001 parameter values for Class-I cities and corresponding adjusted $\mathrm{R}^{2}$ values are given in Table 5. The value of the parameter $\mathrm{z}$ is found to be 0.77 for 1991 and 0.74 for 2001, both are less than one. The computed adjusted $\mathrm{R}^{2}$ is significantly high, explaining more than 97 percent of the total variation (See graphs in Figure 2). With the estimated value of $z$ declines over time, implying the slope of the rank size gets flatter and is viewed as indicating that concentration of urban population is increasing over time. Similarly, the performance of the exponential model fits well for cities of Class-II to Class-V (See Figure 3 to Figure 6). The adjusted $\mathrm{R}^{2}$ is significantly high and explains more than 95 percent of variation (See Table 5). Finally, the distribution of Class VI cities has been fitted for 1991 and 2001 by using a 4th degree polynomial equation. Interestingly, the expected distribution exactly matches the observed city size distribution (See Table 5; Figure 7).

The chosen models of Pareto distribution for cities of Class-I size, exponential model for Class-II to Class-V and for Class-VI cities and polynomial model of the $4^{\text {th }}$ degree, have shown encouraging results. The estimated Pareto parameter $\mathrm{z}$ indicates increasing concentration of urban population in cities of population size more than a million (Class-I cities), and it will continue to increase in the future also as the necessary stage in terms of capital investment and industrial activities has been set. This can lead to further deterioration of quality of life in the great cities of India (Kadi and Halingali, 2007). On the other hand, the growth rate of cities other than Class-I have shown consistent decline during 1991-2001, and they exist mainly as service centers with little economic growth. Hence national planners and policy makers must develop policies to stimulate development in smaller cities, and this may help curtail migration from smaller cities to Class-I cities.

In urban research, the study of city size distribution using mathematical models largely deals with cities of large size in excess of a million population. Such cities have reached urban maturity, that is constant growth rate strongly influenced by economic development. Other cities with population less than a million have received less attention, although their number is large, covering the major portion of urban population. These smaller cities have differential growth pattern, not strongly correlated with economic development, and their growth depends largely on the type of service they provide to the surrounding villages, such as marketing, administrative, health, and education facilities. Thus, the growth of Class-I cities in India are governed by economic development, generating employment opportunities, and they attract migrants from other cities of smaller size within and outside a given state. These cities are growing at the

CSP 2010, 37.1-2: $125-150$ 
cost of smaller cities (Kadi and Sivamurthy 1988; Megeri 2002; Kadi and Megeri 2009).

\section{Acknowledgements}

We thank both the referees for their useful comments that have helped us in revising the paper. Responsibility for any errors rests with the authors.

\section{References}

Alperovich, G. A. 1988. "A new testing procedure of rank size distribution." Journal of Urban Economics 23: 251-259.

Alperovich, G. A. 1993. "An explanatory model of city size distribution: Evidence from cross-country data." Urban Studies 30(9): 1591-1601.

Bose, A. 1978. India's Urbanization 1901-2001. New Delhi: McGraw Hill Publishing Company Ltd.

Cardoba, J. C. 2003. On the Distribution of City Sizes. Paper presented in the seminar at the universities of Rochester, Pennsylvania, Carnegie Mellon, University of Pittsburgh, Western Ontario, Cornell, Northwestern and the London School of Economics.

Champernowne, D. 1953. "A model of income distribution." Economic Journal LXIII: 318-351.

Cuberes, David. 2004. "The rise and decline of cities." Available online at: http://economics.uchicago.edu/download/cities3.pdf

Dobkins, L. H. and Y. M. Ioannides. 2000. "Dynamic evolution of the size distribution of U.S.cities," in Economics of Cities: Theoretical Perspectives. J. M. Huriot and J. F. Thesse (eds.), Cambridge, MA: Cambridge University Press. Pp. 217-261.

Draper, N. R. and H. Smith. 1998. Applied Regression Analysis. New York: John Wiley and Sons. 
Predicting the Growth Pattern of Cities in India Application of Statistical Models

Fujita, Masahisa, Paul Krugman and A. J. Venables. 1999. The Spatial Economics: Cities, Regions and International Trade. Cambridge, MA: The MIT Press.

Gabaix, Xavier. 1999. "Zipf's law for cities: An explanation.” Quarterly Journal of Economics 114(3): 739-767.

Gibrat, R. 1931. Le Inegalites Economiques Applications: (Librairie du Recueil Sirey). Paris, France.

Henderson, J. V. 1982. "The impact of government policies on urban concentration." Journal of Urban Economics 12(3): 280-303.

Hill, B. 1975. "A simple general approach to inference about the tail of a distribution." Annals of Statistics 3(5): 1163-1173.

Kadi, A. S. and M. Sivamurthy.1988. "Inter-state migration in India: 19711981." Canadian Studies in Population 15(1): 37-50.

Kadi, A. S. and B. I. Halingali. 2007. "Growth and Impact of Slums in Urban India." Paper presented at national seminar on recent statistical data analysis and XXIX Annual conference of IASP, held at Banaras Hindu University, Varanasi, October, 26-28.

Kadi, A. S. and Mageri, M. N. 2009. "The growth of cities in India." Demography India 39 in press.

Krugman, Paul. 1996. The Self-organizing Economy. Cambridge, MA: Blackwell Publishers.

Lange, Oskar. 1962. Introduction to Econometrics. New York: Pergamon Press.

Mills, E. S. and C. M. Becker. 1986. Studies in Indian Urban Development. New York: Oxford University Press.

Mageri, M.N. 2002. The Process of Urbanization: A Statistical Analysis. Unpublished Ph.D.thesis submitted to the Karnataka University, Dharwad, India.

Mohan, R.1985. "Urbanization in India's future.” Population and Development Review 11: 619.

CSP 2010, 37.1-2: $125-150$ 
Moonis, Raza, et.al. 1981. "Urbanization and National Development." In M. Honio (Ed.), Urbanization and Regional Development. Marazen, Asia Nagoya.

Nanda, A.R. 1991. Provisional Population Totals. Rural-Urban Distribution, Paper 2 of Series 1. New Delhi: Census of India.

Nishiyama, Yoshihiko and Susumu Osada. 2004. "Statistical Theory of Rank Size Rule Regression under Pareto Distribution.” Discussion paper no. 009, Kyoto University. Available at: http://www.kier.kyotou.ac.jp/coe21/dp/01-10/DP009-nishiyama\&oasada.pdf

Rosen, Kenneth and M. Resnick. 1980. "The size distribution of cities: An examination of Pareto law and primacy." Journal of Urban Economics 8: $165-186$.

Simon, H. 1955. "On a class of skew distribution functions.” Biometrika XXLII: 425-440.

Soo, K. T. 2005. “Zipf's law for cities: A cross country investigation.” Regional Science and Urban Economics 35(3): 239-263.

Zipf, G. K. 1949. Human Behaviour and the Principle of Least Effort: An Introduction to Human Ecology. Cambridge, MA: Addison-Wesley. 